\title{
Thymoma-associated panencephalitis: a newly emerging paraneoplastic neurologic syndrome
}

\author{
Lynda Adaobi Nwabuobi, Jacob Christian Pellinen, Thomas Mark Wisniewski \\ Department of Neurology, NYU Langone Medical Center, New York University School of Medicine, New York, NY 10016, USA.
}

Correspondence to: Dr. Lynda Adaobi Nwabuobi, Department of Neurology, NYU Langone Medical Center, New York University School of Medicine, 550 1st Avenue, New York, NY 10016, USA. E-mail: lynda.nwabuobi@med.nyu.edu

How to cite this article: Nwabuobi LA, Pellinen JC, Wisniewski TM. Thymoma-associated panencephalitis: a newly emerging paraneoplastic neurologic syndrome. Neuroimmunol Neuroinflammation 2017;4:117-23.

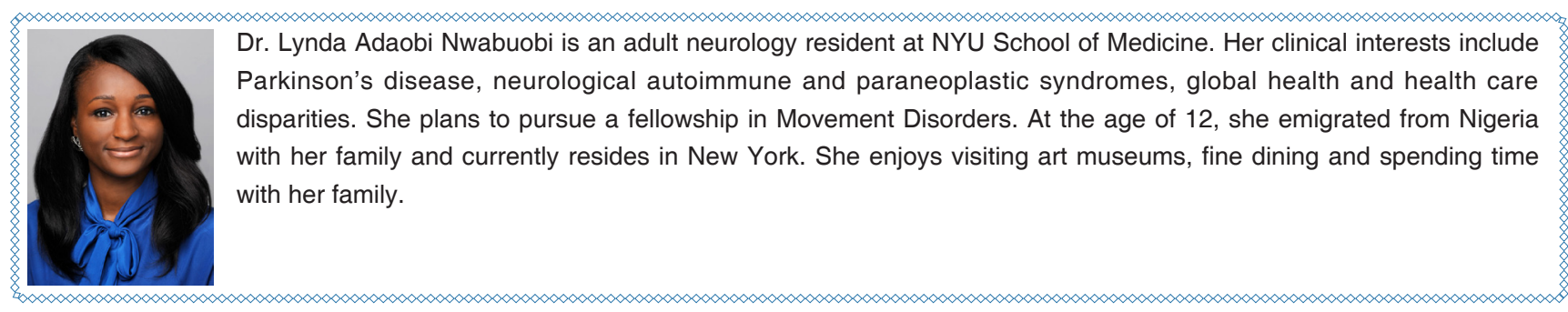

Article history:

Received: 29-11-2016

Accepted: 22-03-2017

Published: 16-06-2017

Key words:

Immunology,

autoimmune diseases,

encephalitis,

thymoma,

paraneoplastic syndrome

\section{ABSTRACT}

Recently, a few case reports of thymoma-associated panencephalitis (TAPE) have brought to light a disease entity that has not been fully characterized. Literature review of TAPE reveals an array of associated neuronal antibodies, with varied responses to thymomectomy with or without immunotherapy. This report describes a case of TAPE and proposes that the GABA receptor antibody is a potential target antigen driving the immune process in this disease entity. Treatment-wise, early thymomectomy consistently improves the overall course of disease. Further study of such cases will be critical in clarifying the mechanisms of disease, improving early diagnosis, and developing targeted approaches to treatment.

\section{INTRODUCTION}

Thymomas are often associated with paraneoplastic neurologic syndromes (PNS) as they have the propensity to express different autoantibodies against neuronal antigens, many of which clinical pathogenicity have not been established. ${ }^{[1,2]}$ Quite rarely, thymomas have been associated with limbic encephalitis, a wellcharacterized neurological syndrome that presents with memory impairment, behavioral changes, and 
seizures. ${ }^{[3]}$ The target antigen when it manifests in thymomas is largely unknown, however, some cases have reported antibodies to $\alpha$-amino-3-hydroxy-5methylisoxazole-4-proprionic acid receptor, leucinerich glioma inactivated 1 protein (LGI1), contactin associated protein 2 (Caspr2), and glutamic acid decarboxylase (GAD). ${ }^{[4]}$ A new entity has been described in a few cases of paraneoplastic encephalitis associated with thymomas, with lesions extending beyond the mesial temporal lobe structures.

\section{CASE REPORT}

A 35-year-old man presented with a 2-week history of seizures, poor appetite, generalized headaches and nausea. Neurologic assessment revealed poor attention, orientation and memory loss, without clinical seizures. Computed tomography head showed multiple cortical hypodensities, prompting an magnetic resonance imaging (MRI) brain, which revealed multiple foci of cortical hyperintensity involving the medial left frontal cortex, the right dorsal aspect of the insula and adjacent right temporal cortex as well as the posterior left temporal cortical medullary junction and the medial posterior left temporal cortex and lateral cortex [Figure 1]. Electroencephalogram revealed hyperexcitability over the right temporal region and frequent focal seizures and he was empirically treated with IV acyclovir, lacosamide and levetiracetam. Cerebral spinal fluid (CSF) analysis revealed protein of $0.51 \mathrm{~g} / \mathrm{L}$, glucose of $3.5 \mathrm{mmol} / \mathrm{L}, 3 \times 10^{-6} / \mathrm{L}$ red blood cells and $9 \times 10^{-6} / \mathrm{L}$ white blood cells $(76 \%$ lymphocytes, $18 \%$ monocytes, $6 \%$ neutrophils). CSF and serum studies were also positive for neuronal antibodies to GAD $[3.93 \mathrm{nmol} / \mathrm{L}$ in the CSF (normal < $0.02 \mathrm{nmol} / \mathrm{L}$ ), $>250.0 \mathrm{kJU} / \mathrm{L}$ in the serum (reference range 0-5 kJU/L)], VGKC-complex antibodies [159 pmol/L in the CSF (reference range $0-31 \mathrm{pmol} / \mathrm{L}$ ), $98 \mathrm{pmol} / \mathrm{L}$ in the serum (reference range 0-31 pmol/L)], CRMP5 (reflex titer < 1:240; positive western blot), and AchR [binding antibody $17.5 \mathrm{nmol} / \mathrm{L}$ in the CSF (normal $<0.02 \mathrm{nmol} / \mathrm{L}$ ), and $142.8 \mathrm{nmol} / \mathrm{L}$ in the serum (reference range $0.0-0.4 \mathrm{nmol} / \mathrm{L}$ )]. Additionally, serum studies revealed presence of systemic antibodies to thyroperoxidase (37.8 kIU/L, reference range $0-5.5 \mathrm{kJU} / \mathrm{L})$, thyroglobulin ( $372.2 \mathrm{kIU} / \mathrm{L}$, reference range $0-5 \mathrm{kIU} / \mathrm{L})$, Ro/SSA (6.8 Al, reference range $<1 \mathrm{Al}$ ), and an ANA titer of 80 (reference range $0-40$ ) with a nucleolar pattern. A paraneoplastic syndrome was suspected, and full body imaging revealed a large multilobulated right anterior mediastinal mass, interfacing multiple right-sided mediastinal structures and invading the
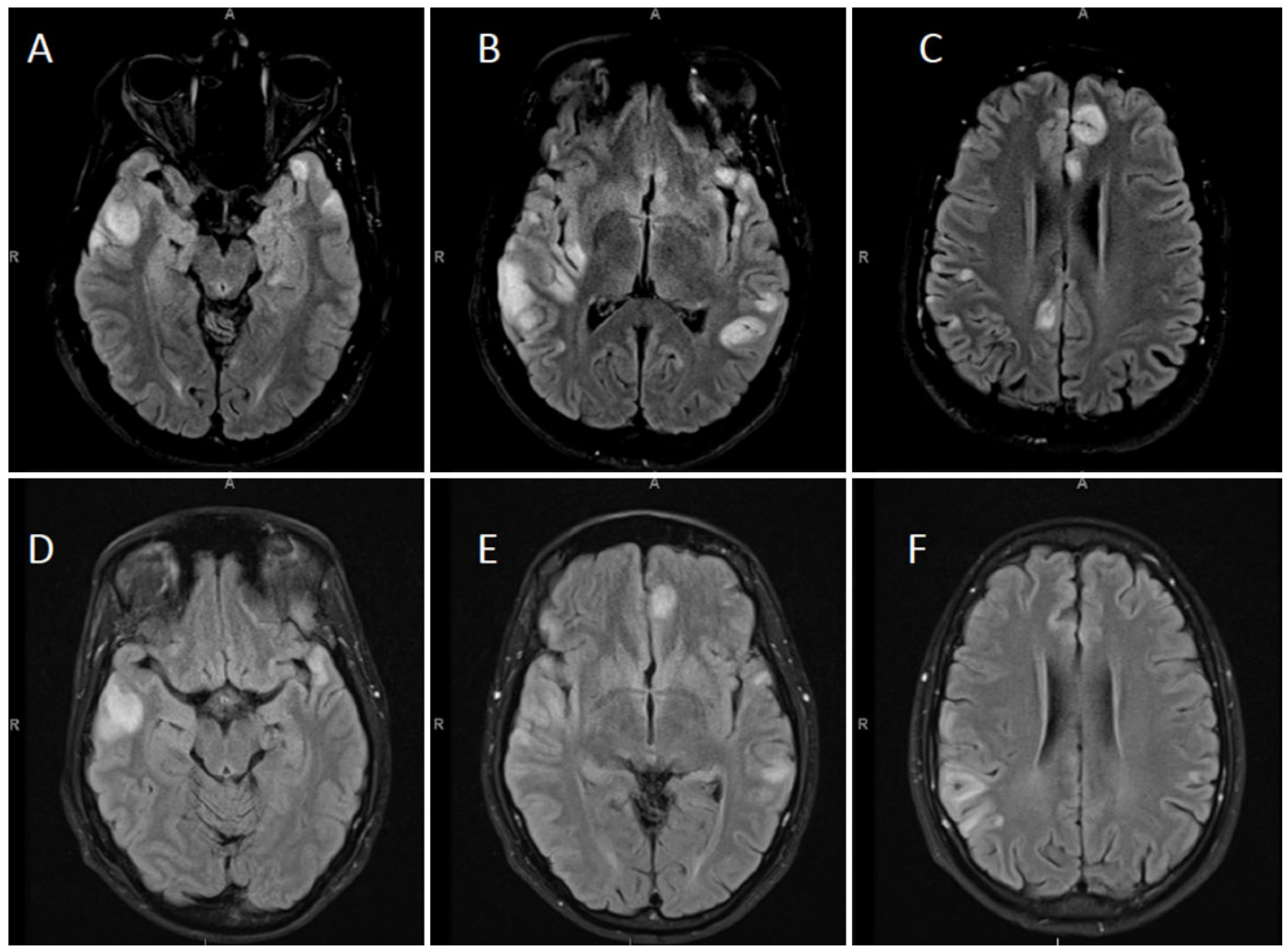

Figure 1: Initial and follow-up magnetic resonance imaging brain scans showing multiple cortically-based signal abnormalities. Images A-C are axial fluid-attenuated inversion recovery images showing multifocal elevated cortical T2/FLAIR signal intensity with associated swelling with involvement of the adjacent subcortical white matter from patient's initial presentation. There was no contrast enhancement, and there was no definite involvement of the deep gray structures, brainstem, or cerebellum. Images D-F are follow up images approximately two weeks later that reveal overall improvement, for instance, previously seen abnormality along the medial left frontal lobe, and in the posterior right insular lesion improved 
bilateral lung apices. This mass was later confirmed to be a metastatic type B2, stage III thymoma via biopsy and after resection [Figure 2]. The patient was treated with intravenous methylprednisolone $(1 \mathrm{~g} /$ day for 10 days) followed by $0.4 \mathrm{~g} / \mathrm{kg}$ daily immunoglobulin (IVIG) for total of 4 days. He had significant improvement in his mental status with the first dose of steroids. Repeat imaging 2 weeks after initial presentation showed improvement in the cortical lesions, specifically, decrease in the abnormal fluid-attenuated inversion recovery (FLAIR) hyperintensities [Figure 1]. Further treatment included chemotherapy with cisplatin, doxorubicin, and cyclophosphamide given the invasive nature of the thymoma. Prior to thymomectomy, his course was complicated by gastrointestinal dysmotility syndrome thought to be a result of his paraneoplastic syndrome. He underwent a successful thymomectomy with complete resection approximately 3 months after initial presentation, and continued to improve thereafter.

\section{DISCUSSION}

Based on literature review, our patient is one of the very few reported cases of thymoma-associated panencephalitis (TAPE). These cases highlight the similar neurological symptoms at presentation -seizures, confusion, and memory loss being the most common -- with a constellation of positive antibodies and different responses to treatment [Table 1]. The similar presentations and MRI findings in these patients support TAPE as a distinct disease entity and autoimmune disorder. Our case was unique as our patient was found to have multiple neuronal and non-neuronal antibody responses and had a drastic improvement in his clinical symptoms with just immunotherapy, unlike other cases that showed improvement after thymomectomy and/or extensive immunotherapy. In order to further characterize TAPE as a paraneoplastic syndrome, antibody associations need to be elicited.

In reviewing the prior reported cases, these patients can have a variety of autoantibodies as seen in Table 1, the most common being AchR, present in 9 of 16 cases, with 5 having symptoms of myasthenia gravis (MG). This is not surprising as up to $37 \%$ of patients with thymic tumors but without MG have been reported to have positive antibody titers to AchR. ${ }^{[5]}$ Voltage-gated potassium channel (VGKC) was the 2nd most common antibody seen in 5 patients. It has been proven that the antibodies to VGKC actually target the associated proteins LGI1 and Caspr2, and not the channel itself, therefore rendering the term, "antibodies to VGKC" obsolete. ${ }^{[6]}$ Antibodies to LGI1 and Caspr2 were present in 3 and 1 of the patients, respectively. Both CRMP-5 and GAD were occasionally present among the cases. The presence of GAD antibodies in thymoma is associated with stiff person syndrome and unlikely to manifest as encephalitis. ${ }^{[1]}$ CRMP-5 has been shown to be a marker of immune response initiated by thymomas in different PNS, and therefore, may not be neuropathogenic. ${ }^{[7]}$ Antibodies against $\mathrm{Hu}, \mathrm{Ri}$, and Yo were the least common, absent in $50 \%$ of the patients. Review of associated antibodies in these previously reported cases does not show a clear pattern, and it is unclear which antibodies are actually pathologic and which ones are incidental. Of significant importance, Petit-Pedrol et al. ${ }^{[8]}$ recently reported 6 patients who presented very similarly to
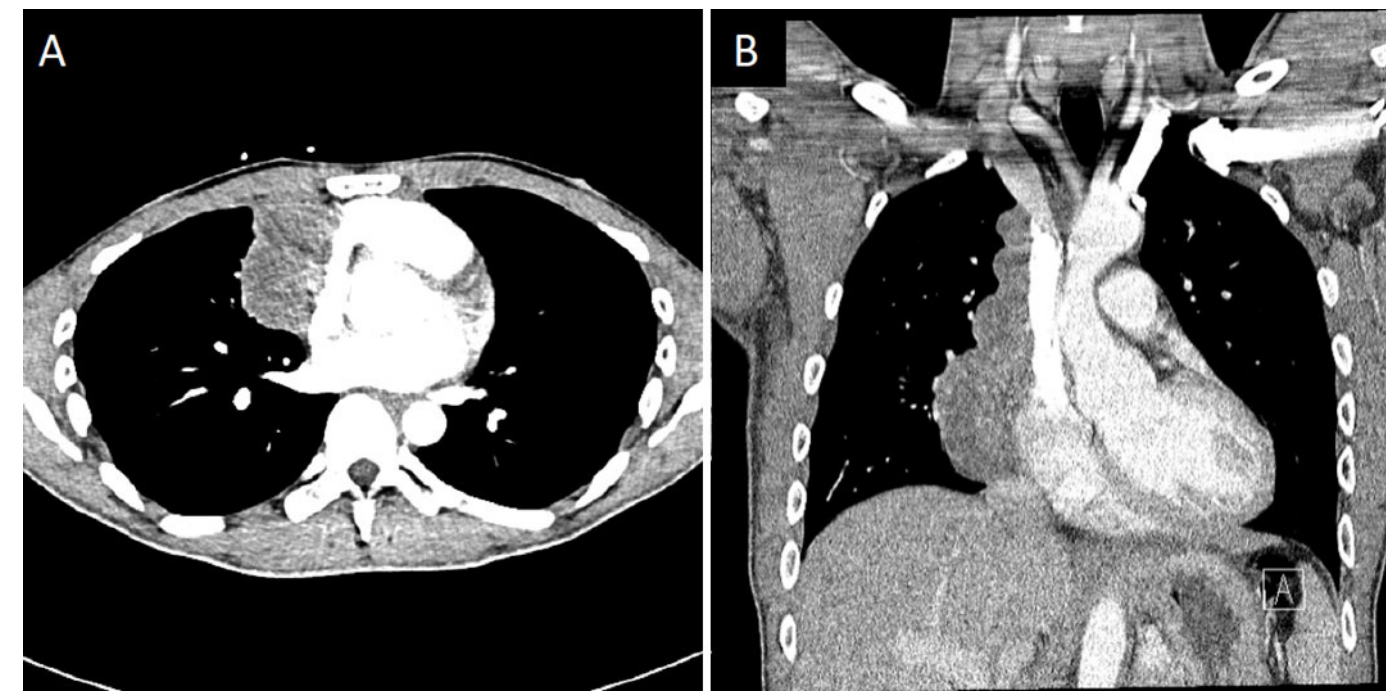

Figure 2: Computed tomography chest showing large right mediastinal mass. Contrast-enhanced computed tomography images (A: axial; B: coronal), showing a large multilobulated right anterior mediastinal mass measuring $6.0 \mathrm{~cm} \times 4.7 \mathrm{~cm}$ in transverse dimension by approximately $13 \mathrm{~cm}$ in craniocaudal dimension. There was found to be mass effect with mild compression of the right atrium and superior vena cava (though patent). Thymoma was suspected, and proven later on biopsy 


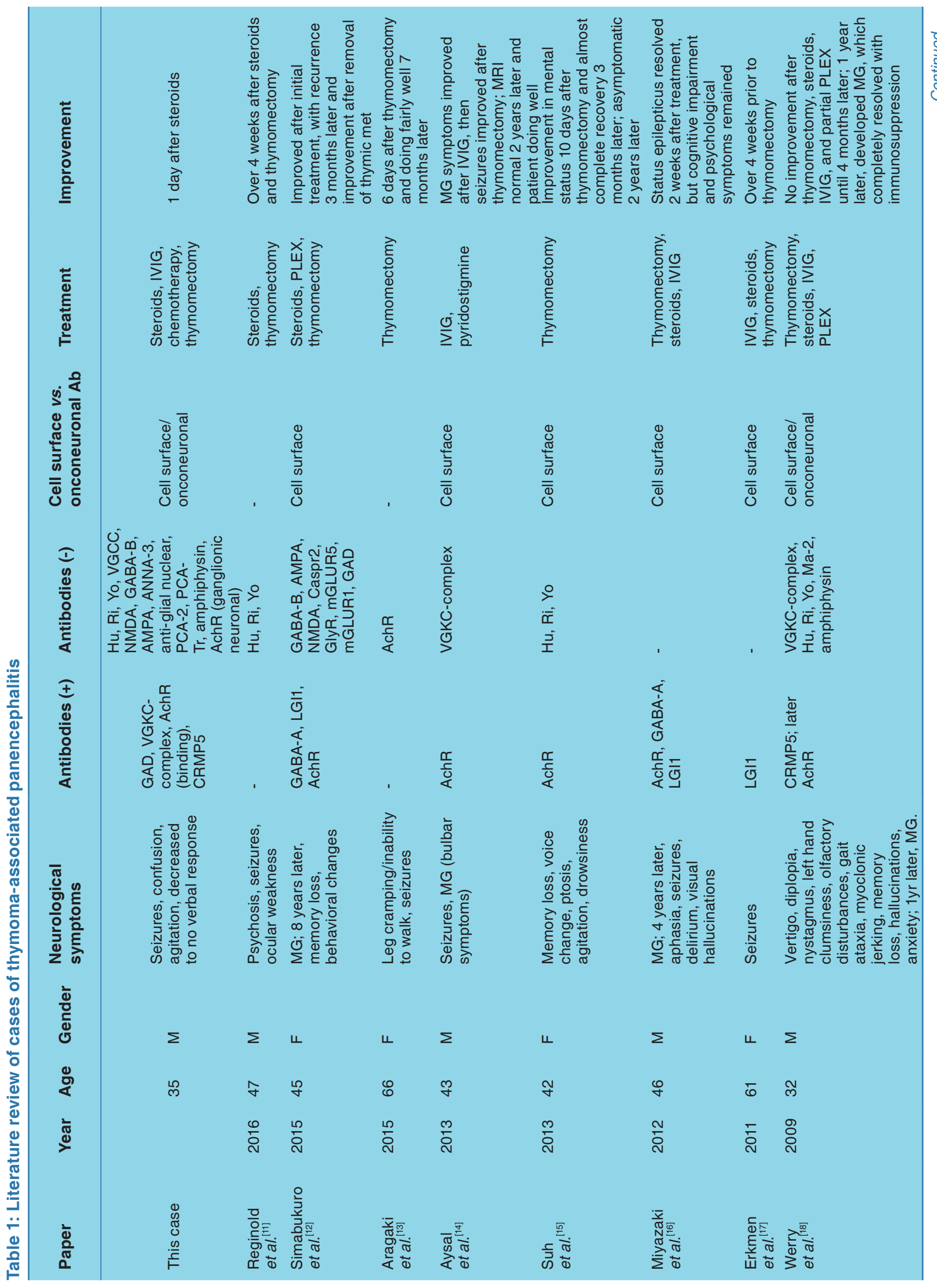




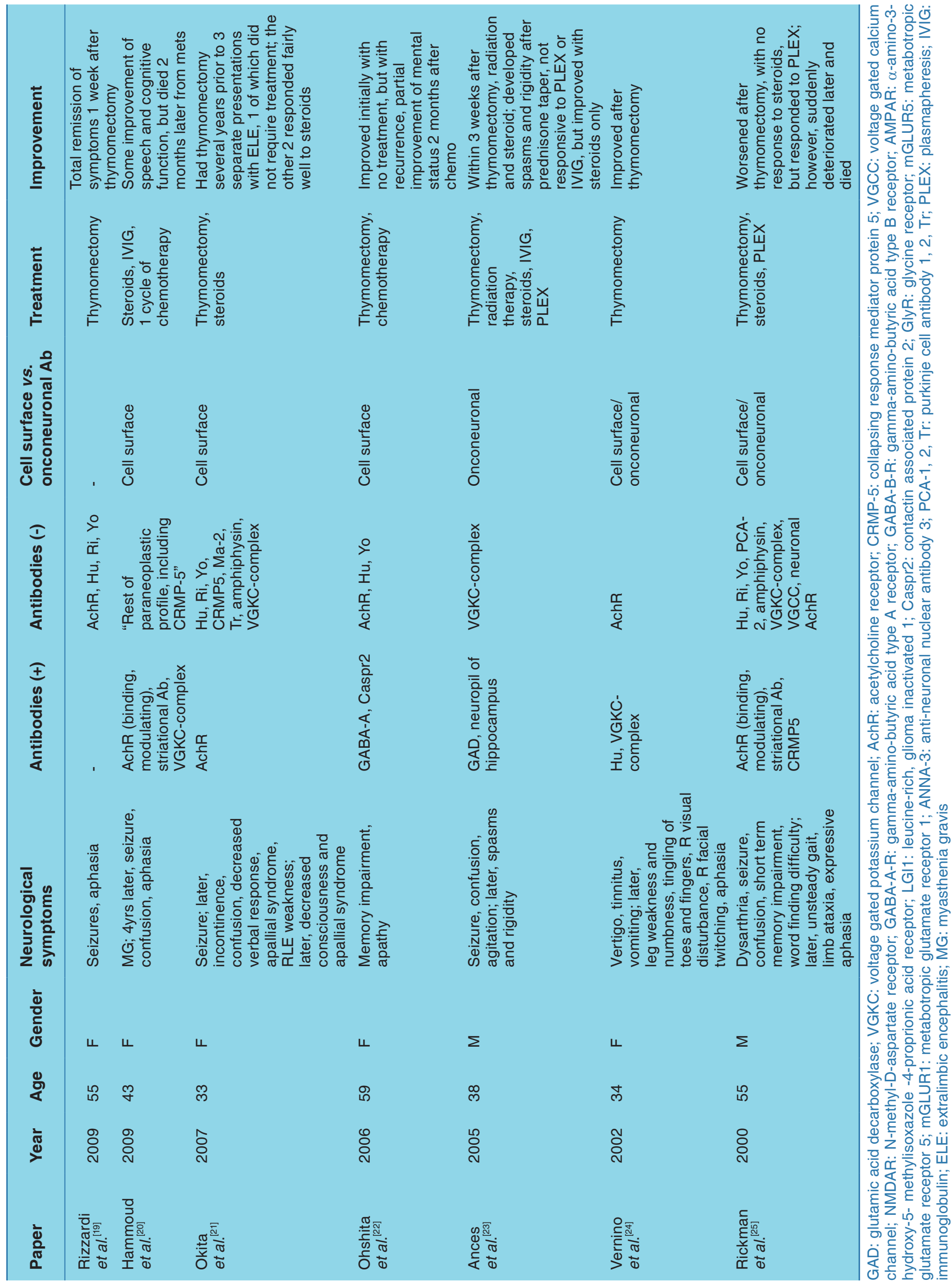


our patient (behavioral/cognitive changes, seizures, multifocal T2/FLAIR lesions) with high titer CSF and serum antibodies to $\mathrm{GABA}_{A} R$. These patients did not have evidence of thymoma, however, did have other evidence of immune dysregulation, including the presence of other antibodies. ${ }^{[8]}$ Most importantly, the $\mathrm{GABA}_{\mathrm{A}} \mathrm{R}$ antibody was shown to have pathogenic effects on the antigen, specifically, downregulation of receptors in cultured neuronsand patients usually responded to therapy. ${ }^{[8,9]}$ Furthermore, Ohkawa et al. ${ }^{[9]}$ retested the sera of 2 patients previously with TAPE via a nonbiased proteomic method and identified antibodies to $G_{A B A} R$. Our patient was not tested for this antibody, however, his clinical findings, brain imaging, and response to therapy are suggestive of $\mathrm{GABA}_{\mathrm{A}} \mathrm{R}$ associated panencephalitis.

One of the setbacks in managing TAPE is early recognition as there are so few cases reported. PNS associated with antineuronal cell surface antibodies are often highly responsive to treatment, while those with onconeuronal antibodies have a generally poor response. ${ }^{[10]}$ Review of the cases shows responses to treatments differed without any clear correlation to antibody types. Every patient received thymomectomy with partial or full response followed by a combination of steroids, plasmapheresis and/or IVIG. This suggests that early surgical removal of tumors with or without immunotherapy could provide a good chance of recovery from disease. Albeit, the presence of both cell-surface and onconeuronal antibodies in our patient may indicate a poor prognosis despite his initial rapid improvement.

\section{Authors' contributions}

Concept, literature search, preparation, editing and revision of manuscript: L. Nwabuobi

Patient data and imaging acquisition, editing and revision of manuscript: J. Pellinen

Supervision and revision of manuscript: T. Wisniewski

\section{Financial support and sponsorship None.}

\section{Conflicts of interest}

There are no conflicts of interest.

Patient consent

Verbal consent was obtained from the patient.

\section{Ethics approval \\ Not applicable.}

\section{REFERENCES}

1. Marx A, Willcox N, Leite MI, Chuang WY, Schalke B, Nix W, Strobel
P. Thymoma and paraneoplastic myasthenia gravis. Autoimmunity 2010;43:413-27.

2. Kondo K, Yoshizawa K, Tsuyuguchi M, Kimura S, Sumitomo M, Morita J, Miyoshi T, Sakiyama S, Mukai K, Monden Y. WHO histologic classification is a prognostic indicator in thymoma. Ann Thorac Surg 2004;77:1183-8.

3. Evoli A, Lancaster E. Paraneoplastic disorders in thymoma patients. $J$ Thorac Oncol 2014;9:S143-7.

4. Graus F, Titulaer MJ, Balu R, Benseler S, Bien CG, Cellucci T, Cortese I, Dale RC, Gelfand JM, Geschwind M, Glaser CA, Honnorat J, Hoftberger R, Iizuka T, Irani SR, Lancaster E, Leypoldt F, Pruss H, Rae-Grant A, Reindl M, Rosenfeld MR, Rostasy K, Saiz A, Venkatesan A, Vincent A, Wandinger KP, Waters P, Dalmau J. A clinical approach to diagnosis of autoimmune encephalitis. Lancet Neurol 2016;15:391-404.

5. Ohta M, Itoh M, Hara H, Itoh N, Nishitani H, Hayashi K, Ohta K. Anti-skeletal muscle and anti-acetylcholine receptor antibodies in patients with thymoma without myasthenia gravis: relation to the onset of myasthenia gravis. Clin Chim Acta 1991;201:201-5.

6. Lai M, Huijbers MG, Lancaster E, Graus F, Bataller L, Balice-Gordon $\mathrm{R}$, Cowell JK, Dalmau J. Investigation of LGI1 as the antigen in limbic encephalitis previously attributed to potassium channels: a case series. Lancet Neurol 2010;9:776-85.

7. Yu Z, Kryzer TJ, Griesmann GE, Kim K, Benarroch EE, Lennon VA. CRMP-5 neuronal antibody: marker of lung cancer and thymomarelated autoimmunity. Ann Neurol 2001;49:146-54.

8. Petit-Pedrol M, Armangue T, Peng X, Bataller L, Cellucci T, Davis R, McCracken L, Martinez-Hernandez E, Mason WP, Kruer MC, Ritacco DG, Grisold W, Meaney BF, Alcala C, Sillevis-Smitt P, Titulaer MJ, Balice-Gordon R, Graus F, Dalmau J. Encephalitis with refractory seizures, status epilepticus, and antibodies to the GABAA receptor: a case series, characterisation of the antigen, and analysis of the effects of the antibodies. Lancet Neurol 2014;13:276-86.

9. Okhawa T, Satake S, Yokoi N, Miyazaki Y, Ohshita T, Sobue G, Takashima H, Watanabe O, Fukata Y, Fukata M. Identification and characterization of GABAa receptor autoantibodies in autoimmune encephalitis. J Neurosci 2014;34:8151-63.

10. Hoftberger R, Rosenfeld MR, Dalmau J. Update on neurological paraneoplastic syndromes. Curr Opin Oncol 2015;27:489-95.

11. Reginold W, Ninan K, Coret-Simon J, Haider E. Paraneoplastic limbic and extra-limbic encephalitis secondary to a thymoma mimicking an acute stroke. Can J Neurol Sci 2016;43:420-3.

12. Simabukuro MM, Petit-Pedrol M, Castro LH, Nitrini R, Lucato L, Zambon AA, Silva, LG, Fortes GC, Soares Neto HR, Dalmau JO. GABAa receptor and LGI1 antibody encephalitis in a patient with thymoma. Neurol Neuroimmunol Neuroinflamm 2015;2:e73.

13. Aragaki M, Iimura Y, Teramoto K, Sato N, Hirose K, Hasegawa N. Paraneoplastic extralimbic encephalitis associated with thymoma: a case report. Ann Thorac Cardiovasc Surg 2015;21:300-402.

14. Aysal F, Baybas S, Selcuk HH, Sozmen V, Ozturk M, Kucukoglu H, Urer NH. Paraneoplastic extralimbic encephalitis associated with thymoma and myasthenia gravis: three years follow up. Clin Neurol Neurosurg 2013;115:628-31.

15. Suh JW, Haam SJ, Song SW, Shin YR, Paik HC, Lee DY. Paraneoplastic encephalitis associated with thymoma: a case report. Korean J Thorac Cardiovasc Surg 2013;46:234-6.

16. Miyazaki Y, Hirayama M, Watanabe H, Usami N, Yokoi K, Watanabe O, Sobue G. Paraneoplastic encephalitis associated with myasthenia gravis and malignant thymoma. J Clin Neurosci 2012;19:336-8.

17. Erkmen CP, Fadul CE, Dalmau J, Erkmen K. Thymoma-associated paraneoplastic encephalitis (TAPE): diagnosis and treatment of a potentially fatal condition. J Thorac Cardiovasc Surg 2011;141:17-20.

18. Werry C, Gotz F, Wurster U, Stangel M, Giess R, Heidenreich F, 
Windhagen A. Paraneoplastic autoimmune encephalitis associated with CV2/CRMP-5 IgG antineuronal antibodies in a patient with thymoma. J Neurol 2009;256:129-31.

19. Rizzardi G, Campione A, Scanagatta P, Terzi A. Paraneoplastic extra limbic encephalitis associated with thymoma. Interact Cardiovasc Thorac Surg 2009;9:755-6.

20. Hammoud K, Kandimala G, Warnack W, Vernino S. Multifocal paraneoplastic cortical encephalitis associated with myasthenia gravis and thymoma. Arch Neurol 2009;66:1407-9.

21. Okita K, Matsukawa N, Hattori M, Yamada K, Takada K, Yamawaki T, Yoshida M, Hashizume Y, Ojika K. Recurrent limbic and extralimbic encephalitis associated with thymoma. Clin Neurol Neurosurg 2007;109:206-9.

22. Ohshita T, Kawakami H, Maruyama H, Kohriyama T, Arimura K,
Matsumoto M. Voltage-gated potassium channel antibodies associated limbic encephalitis in a patient with invasive thymoma. J Neurol Sci 2006;250:167-9.

23. Ances BM, Vitaliani R, Taylor RA, Liebeskind DS, Voloschin A, Houghton DJ, Galetta SL, Dichter M, Alavi A, Rosenfeld MR, Dalmau J. Treatment-responsive limbic encephalitis identified by neuropil antibodies: MRI and PET correlates. Brain 2005;128:1764-77.

24. Vernino S, Eggengerger ER, Rogers LR, Lennon VA. Paraneoplastic neurological autoimmunity associated with ANNA-1 autoantibody and thymoma. Neurology 2002;59:929-32.

25. Rickman OB, Parisi JE, Yu Z, Lennon VA, Vernino S. Fulminan autoimmune cortical encephalitis associated with thymoma treated with plasma exchange. Mayo Clin Proc 2000;75:1321-6. 